\title{
LOS BUCANEROS Y LA DEFENSA DE LA COSTA DEL PACIFICO A FINES DEL SIGLO XVII EN QUITO: EL CASO DE LAS BARBACOAS
}

\author{
Kris E. Lane ${ }^{2}$ \\ Universidad de Miami
}

1 Traducido del inglés por Ivonne L. Tovar Mora, Centro de Investigaciones de Historia Colonial

N.T. En la realización de esta traducción se han respetado todas las palabras que el autor incluyó en español y destacó con bastardeas en la versión inglesa de este artículo.

2 Mis más sinceros agradecimientos al profesor Stuart Schwartz y a los incansables historiadores del Taller Colonial en la Universidad de Minnesota. Agradezco también a los revisores anónimos de esta revista, por sus, por sus comentarios y estímulos; cualquier equivocación es de mi estricta responsabilidad. Los recursos económicos fueron posibles gracias a la beca FulbrightHays otorgada para viajar al Ecuador (1994-95).
Desde julio de 1680, y por más de una década, la población de la provincia minera de las Barbacoas, localizada en el húmedo litoral del Pacífico del territorio de la actual Colombia, afrontó una serie de encuentros desagradables con bucaneros, tanto ingleses como franceses. Esta era la primera vez, desde comienzos de 1640, que intrusos extranjeros amenazaban al Pacífico español y a Las Barbacoas, una sub-provincia de la Audiencia, de Quito, colonizada a principios del siglo XVII, que no estaba preparada para enfrentar asaltantes armados. Los campos mineros y los centros comerciales de las Barbacoas, accesibles por mar, no sufrieron durante el siglo XVII incursiones piratas, a pesar de las múltiples invasiones destructoras que los bucaneros efectuaron en numerosas poblaciones de la costa que corre desde la Baja California hasta el sur de Chile. Como se demostrará, las gestiones para la defensa local jugaron un papel central en este sentido, sin embargo, también fue cierto que a los bucaneros se les informaba muy poco acerca de los tesoros de la región. El caso de las Barbacoas es tal vez el único del que se conservan informes locales sobre las actividades de los piratas. Estos se conservan en los archivos de Quito y Popayán y le proporcionan al historiador una visión muy particular sobre los sobresaltos vividos por las localidades, a raíz de la amenaza que representaban sus ataques. Estos documentos permiten 
apreciar claramente, que las consecuencias políticas y financieras de la bucanería en esta remota región, fueron aún mayores que el temor que causaban, ya que repercutieron profundamente en su interior, ocasionándole grandes daños, incluso cuando los ataques de los enemigos fracasaron. Este ensayo intentará llamar la atención sobre los múltiples efectos que tuvo la piratería sobre la vida local en una región fronteriza, al caracterizar los eventos que rodearon tres momentos diferentes de los encuentros entre los piratas y los residentes de las Barbacoas. En efecto, los tres encuentros, ocurridos en 1680,1684 y 1689, correspondieron a tres momentos diferentes de la actividad de los piratas en el Pacífico español, y serán tratados en detalle, después de un breve análisis introductorio sobre la piratería a finales del siglo XVII y su contexto, y de un breve análisis del trasfondo histórico de la poco estudiada región de las Barbacoas.

El Pacífico español se había mantenido en una constante agitación debido a los intermitentes ataques extranjeros efectuados desde los años de 1570, pero nunca en un grado tal como en los años de 1680, ni de forma constante como los experimentaron los españoles del mar Caribe. ${ }^{3}$ Existían muchas razones por las cuales se presentó esta situación, pero el factor geográfico fue el más importante. Sólo se podía llegar al Mar del Sur, como se llamaba al mar Pacífico, cruzando por tierra Panamá o algún lugar de Centroamérica, o bien intentando navegar hacia el sur alrededor del continente suramericano, generalmente a través del peligroso estrecho de Magallanes. Cruzar desde las Indias Orientales hasta las costas Occidentales de la Nueva España o Perú no se consideró generalmente una opción, sino hasta el siglo XVIII.

A pesar de estas barreras naturales, a comienzos de 1575 los piratas hallaron la vía hacia el mar del Sur y hostigaron los navíos y poblados españoles. Durante dicho año John Oxenham, uno de los piratas de la reina Isabel que operaba en el Caribe, logró pasar al Pacífico por el este de Panamá. Las invasiones de Oxenham tuvieron éxito en un comienzo, pero muy pronto éste cayó en manos de la Inquisición de Lima, donde lo ejecutaron por hereje. Francis Drake, un primer socio de Oxenham, le siguió muy pronto a través del estrecho de Magallanes en 1579, y su famoso viaje alrededor del mundo incluyó la captura de varios navíos españoles a lo largo de la costa peruana. En 1580 y 1590 Thomas Cavendish y Richard Hawkins, respectivamente, siguieron la ruta de Drake, con resultados varios. Sin embargo, sus ataques, comparados con las invasiones de la época de la Reina Isabel en el Caribe y en el Atlántico oriental durante estos años, significaron una amenaza relativamente pequeña en el Mar del Sur.

\footnotetext{
3 Este resumen sobre la actividad de los piratas en el Pacífico español se ha hecho con base en las obras de Peter Gerhard, Pirales of the West Coast of New Spain, 1575-1742, Glendale, OA, Arthur H. Clark, 1960 y Peter Bradley, The Lure of Peru: Maritime Intrusión into the South Sea. 1598-1701, Nueva York, St Maitin's Press, 1988. Estos estudios resultan de gran interés e importancia ya que integran las fuentes oficiales españolas y extranjeras.
} 
La situación de la mayoría de piratas solitarios o corsarios, que operaban en uno o dos barcos, cambió dramáticamente con el aumento de las hostilidades entre holandeses y españoles a finales del siglo XVI. A comienzos de 1598 las expediciones que penetraron el Pacífico español, a través de diversas rutas por el sur, incluido el rodeo por Cabo de Hornos, fueron expulsadas de las Provincias Unidas. Los primeros viajes, aquellos de Olivier van Noort y Jacob Mahu (1598 -1601), tuvieron muy poco éxito; regresaron de la costa sur de Chile a Europa sin botín. Sin embargo, los viajes realizados en los años de 1610 y 1620, bajo el patrocinio de las compañías holandesas del Oriente y de las Indias Occidentales, causaron gran daño y preocupación a lo largo de la región. La respuesta de los españoles fue la de habilitar una Armada, la Armada Real del Mar del Sur, pero en julio de 1615 este pequeño escuadrón, con su flota de cuatro barcos y dos yates, fue prácticamente destruido frente a Cañete, al sur de Lima, en un encuentro con Joris van Speilbergen. A este desastroso enfrentamiento le siguió una expedición de once barcos holandeses dirigidos por Jacques l'Hermite y Hugo Schapenham, una década más tarde. La expedición de l'Hermite-Schapenham no fue tan exitosa como su tamaño lo hubiera permitido, pero Callao, el puerto de Lima, fue bloqueado durante unos meses y Guayaquil, puerto de la Audiencia de Quito, fue saqueada en 1624. El otro viaje holandés realizado hacia la costa occidental de la América española durante este período ocurrió entre 1642-43, pero esta expedición, comandada por Henclrick Brouwer, nunca alcanzó a llegar más allá del Sur de Chile.

Aparte de una expedición inglesa igualmente corta y poco rentable, dirigida hacia Chile entre 1669-70 por John Narborough, los españoles experimentaron un largo respiro de ataques enemigos en el mar del Sur. Como resultado de este período de calma, roto momentáneamente por la marcha que realizó Henry Morgan por tierra hacia Panamá en enero de 1671, se debilitaron las defensas marítimas y terrestres españolas en el Pacífico. Se dejaron deteriorar los barcos de la armada y los fuertes construidos alrededor de Callao, Guayaquil y otras ciudades costeras fueron abandonados. La ausencia de una amenaza pirata y el débil cumplimiento de las restricciones comerciales entre Perú y la Nueva España, hicieron que durante este período renaciera el comercio intercolonial en el Pacífico. ${ }^{4}$ Mientras tanto los bucaneros, un grupo independiente y multinacional de ladrones de mar que operaba en el Caribe desde los años de 1630, enfrentaba nuevas presiones en sus propias aguas. ${ }^{5}$ Después de firmado el Tratado de Madrid de 1670, mediante el cual los piratas fueron declarados fuera de la ley, no sólo a los ojos de los españoles sino también de los ingleses,

4 Para una discusión más general sobre las embarques de mercancía en el Pacífico ver Lawrence A. Clayton, -Trade and Navigation in the Seventeenth Centuiy Viceroyalty of Peru Journal of Latín American Studíes7:1, mayo 1975. Págs. 1-21, y "Local Initiative and Finance in Defense of the Viceroyalty of 'Peru: The development of Self-Reliance», Hispanic American Historical Review, 54:2, mayo 1974. Págs. 284-304. El segundo artículo muestra cómo los comerciantes, y no la corona, fueron en gran medida responsables de la organización de escuadrones navales contra los bucaneros del mar del Sur en los años de 1680 y 1690. 


\section{IA COSTA PACIFICA EN LA EPOCA DE LOS BUCANEROS}

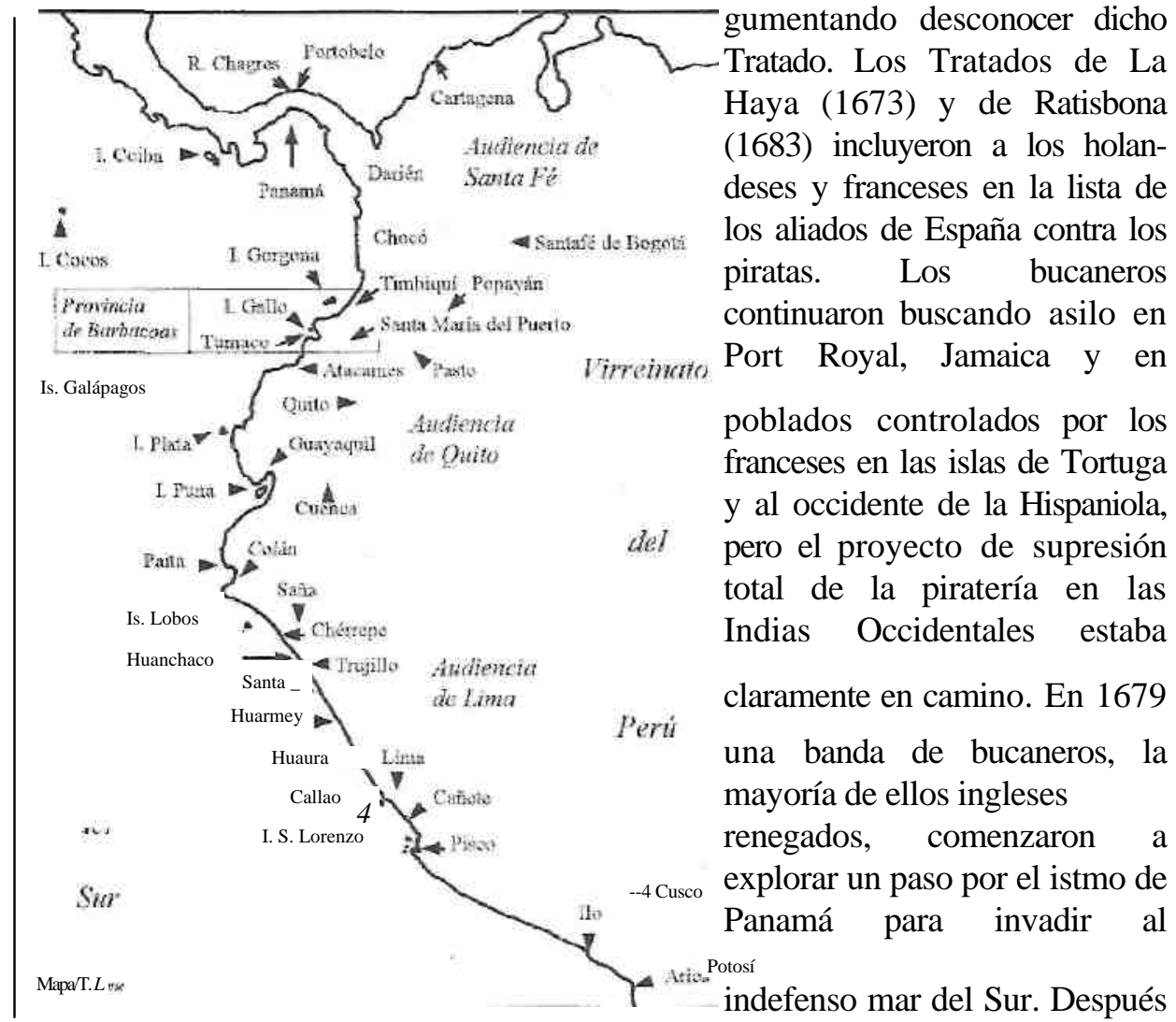

Morgan atacó y destruyó a Panamá, argumentando desconocer dicho Tratado. Los Tratados de La Haya (1673) y de Ratisbona (1683) incluyeron a los holandeses y franceses en la lista de os aliados de España contra los piratas. Los bucaneros continuaron buscando asilo en franceses en las islas de Tortuga aniola, total de la piratería en las charame 1679 la

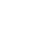

.

de 1683 serían seguidos por otras bandas, francesas e inglesas, y algunas de ellas continuarían navegando estas aguas hasta comienzos de los años de 1690. Estos fueron los bucaneros, que actuaban ilegalmente ante los ojos de sus propios gobiernos, y quienes después de 1680 comenzaron a amenazar a los residentes de las Barbacoas.

La plata de Potosí era su objetivo principal, pero en el momento en que los primeros bucaneros, dirigidos por Bartholomew Sharp, John Coxon y otros más, abrieron

\footnotetext{
5 El término «bucanero» proviene del francés boucan, o personas de la Hispaniola que sirven carne, pero era utilizado para describir una variedad particular de asaltante marítimo que, después de aproximadamente 1630, no contaba con el respaldo de las naciones-estados. En este ensayo el término se aplica específicamente a los piratas anglo-americanos, ingleses, franceses y holandeses activos en el Caribe y el Pacífico español a finales del siglo XVII. Los bucaneros sólo eran ocasionalmente contratados como corsarios o invasores, que contaban con respaldo estatal, en tiempos de guerra (es decir, antes de $1670 \mathrm{y}$ después de 1689); ver Bradley. The Lure of Peru, Pág. 220.
} 
camino hacia el Pacífico, Las Barbacoas era una de las más prominentes regiones mineras del sur de la América española, en lo que al oro se refería. La región del Chocó, más al norte, era igualmente rica en oro, como lo había podido constatar alguno de los bucaneros, aunque aún era una región altamente volátil. Muchos indígenas del Chocó eran tan hostiles hacia los bucaneros como lo eran hacia sus enemigos españoles, y los distritos de oro más consolidados, como Antioquia, Caloto y Chisquío, en la Nueva Granada, y Zaruma en la Audiencia de Quito al sur, se encontraban en la tierra adentro, alejados de las costas, lo que los hacía prácticamente invulnerables. Por entonces, en Chile, la mayoría de los campos de oro alrededor y hacia el sur de Santiago habían sido ya trabajados o abandonados debido a los levantamientos indígenas. Por otro lado, por estos años las minas de las Barbacoas estaban experimentando su primer boom. Estas minas se encontraban aisladas de los grandes centros de población españoles, lo que facilitó el que se convirtieran en objetivos principales de ataques.

Mientras que el bucanero inglés Basil Ringrose y sus compañeros viajaban hacia el sur a lo largo de la costa Pacífica en julio de 1680, uno de los miembros alfabetos de la banda de ladrones de mar de Bartholomew Sharp, dejó esta vaga descripción sobre la tierra montañosa al este de la Isla Gorgona: «...la tierra que vimos era la tierra de Barbacoa [sic], siendo casi todo un país salvaje.». ${ }^{6}$ Esta tierra era conocida por los españoles como la Provincia de las Barbacoas, palabra tomada del Taino para referirse a las casas construidas sobre troncos de madera por los habitantes indígenas. Una amplia región húmeda y selvática, protegida por pantanos laberínticos de manglares, engañosos alfaques de arena, montañas densamente arborizadas y grupos indígenas belicosos, hacían a Las Barbacoas, desde luego, -casi un país salvaje por todos lados». Pero a pesar de que Ringrose no lo podía ver desde su fortín temporal en la isla Gorgona, esta provincia poco poblada y apenas controlada, así como su capital Santa María del Puerto, tenían demasiado interés para un bucanero como él.

Casi todos los ríos que regaban la provincia de Las Barbacoas eran ricos en oro y para entonces muchos se habían poblado con esclavos africanos e indígenas de encomienda. Ambos grupos de trabajadores forzados excavaban y lavaban los arcillosos terraplenes de grava del Telembí, Maguí, Güelmambí, Timbíqui y otros ríos, vigilados por los colonos españoles y mestizos de las regiones montañosas y de ciudades costeras como Guayaquil, Lima y Panamá. Los grupos indígenas de la región, como los Sindaguas, Nulpes, Coaiqueres, Chupas, Guapíes, Boyas y otros, aunque raramente se concentraban en aldeas, incluso después de la conquista, ahora se encontraban reducidos a unas pocas docenas de encomiendas. Aunque en ciertos casos los indí-

6 Basil Ringrose en su South Sea Journal/(julio de 1680), publicado como la IV parte de John Esquemeling (comp.), The Buccaneers of America, being a True Account of the most Remarkable Assaults Comitet of late years on the Coast of the West Indies by the Buccaneers of Jamaica and Tortuga, both English and French, Glorieta, NM, Río Grande Press, 1992 ( ecl. facsímil de 1684), Pág, 341. 
genas no desempeñaban labores propiamente mineras, de todos modos permanecían asociados de alguna forma con estas actividades. Muchos eran forzados a desbrozar el bosque con el fin de cultivar bananos para los esclavos, pescar y salar los peces, trabajar como remeros de las canoas y construir casas de techo de paja, labores que nunca hicieron de forma voluntaria. Quienes escapaban eran cazados en los matorrales, tratados como yndios cimarrones (runaway indians) y esclavizados. A pesar de todos estos problemas de insubordinación laboral y de posteriores estragos causados por enfermedades, las minas de las Barbacoas comenzaron a producir generosámente en los años de $1670 .^{7}$

Los bucaneros que escoraban o reparaban los cascos de sus navíos en la isla Gorgona a principios de los años de 1680, no fueron los primeros europeos en mantenerse desinformados acerca de lo que existía más allá de los mangles, hacia el este de donde se encontraban. En 1526 Francisco Pizarro y su hueste no pudieron penetrar las densas junglas que se encontraban a lo largo de la costa desde Panamá hasta Atacames (hoy en día Ecuador). Gorgona, la misma isla que le proporcionó a Ringrose y Sharp resguardo y comida segura unos 150 años más tarde, fue el hogar de Pizarro por unos siete meses, mientras esperaba a Diego de Almagro y a su compañía de refuerzos. ${ }^{8}$ Este sitio de descanso, junto con la sureña Isla del Gallo, le permitió a los españoles reagruparse antes de entrar al Perú a través de su vulnerable costa desértica, un terreno más familiar, que permitió que un pequeño número de españoles utilizara su más sorprendente ventaja, el caballo. Por otro lado, el litoral húmedo permaneció como territorio indígena por casi un siglo y su conquista no sería tan gloriosa como la de los Incas. Desde finales del siglo XVI hasta mediados del XVII, canoas llenas de soldados españoles con sus esclavos y guías indios desaparecieron en la jungla costera, perdidos, hambrientos, enfermos $y$ a menudo emboscados. Los primeros campos mineros o reales de minas, fueron rápidamente arrasados y algunos lo fueron de raíz, de tal manera que hoy día no pueden ser localizados con exactitud.

Entre 1597 y 1599 se discutieron en Quito una serie de tratados entre los españoles y los jefes afro-indígenas de la región de las Barbacoas, en gran medida como respuesta a la amenaza de los primeros piratas y corsarios ingleses, sobre todo Francis Drake, Thomas Cavendish y Richard Hawkins. Estas deliberaciones fueron dirigidas por el presidente de la Audiencia de Quito. Juan del Barrio Sepúlveda, quien acordó regocijos y obsequios a varios caciques costeros, entre ellos al llamado «Caudillo Zambo» de

7 Roten C West, Colonial Placer Mining in Colombia, Baton Rouge, Louisiana State University Press, 1952, Págs. 18 - 20, discute brevemente lo relativo al territorio que comprendía el distrito de las Barbacoas en este periodo. El presente ensayo se basa más que todo en fuentes documentales y en él se ha delimitado ese distinto en fundón de la documentación encontrada en el Archivo Nacional de Historia en Quito, Ecuador. Ver Kris Lane, «Mining the Margins: Precious Metals Extraction and Forced Labor Regimes in the Audiencia of Quito, 1534-1821», Ph. Diss. University of Minnesota, 1996, Págs. 71-77.

8 El Inca Garcilaso describe esta llegada en detalle The Inca: The Royal Commentaries of the Inca, Garciaso de la Vega, 1539-1616, Alain Gheerbrant, ed, Nueva York, Orion Press, 1961, Pág. 366. 
Esmeraldas y a seis jefes de Las Barbacoas. ${ }^{9}$ A cambio de su promesa de no aliarse con invasores extranjeros, prometer paso seguro para las víctimas de naufragios de buques españoles que ocurrieran a lo largo de su costa, y de aceptar la presencia de un fraile mercedario, los diferentes caciques del Pacífico recibieron adornos europeos y orientales, junto con artículos útiles, como cuchillos, hachas y agujas de coser. Más importante aún fue la promesa de una medida de soberanía. Incluso Alonso Yllescas, el cacique de origen africano, fue nombrado gobernador de su propio territorio de Esmeraldas. ${ }^{10}$

A la luz de la amenaza pirata, los españoles habían optado por otorgar un grado inusual de autonomía a estos caudillos costeros. Una política de compromisos similares con los grupos indígenas de la frontera fue revivida en la época de los ataques de los bucaneros. Sin embargo, como en tantos otros casos de tratados coloniales, los españoles olvidaron sus promesas de los años de 1590, tan pronto como el peligro había pasado. La tentación del oro y el deseo de tener sujetos a los indios sobrepasaba la necesidad de tener aliados autónomos. Hacia 1600 se comenzaron a expedir órdenes de entradas o ataques armados contra las posesiones nativas desde las ciudades y villas andinas de Popayán, Pasto, Ibarra y Quito. La posición de la Audiencia era aparentemente ambivalente, aunque no completamente opuesta a las entradas, puesto que poblar la costa era potencialmente más riesgoso que dejársela a los indígenas. Como John Leddy Phelan lo ha anotado, los funcionarios de Quito, entre ellos el presidente de la Audiencia Antonio de Morga (1615-36), defendieron con ahínco la conquista y poblamiento de la costa norte. Morga y sus seguidores esperaban crear un puerto en la provincia de Esmeraldas o de Barbacoas, para unir la región de Quito de forma más directa con Panamá. Sin embargo, el virrey peruano fue disuadido de apoyar este proyecto, debido a que se consideró que aumentaba la vulnerabilidad del área y podía dificultar su defensa (en ese período frente a los ataques de los holandeses), así como por las protestas vociferantes de los comerciantes limeños. ${ }^{11}$ Teniendo en cuenta las presiones fiscales, en gran parte debido a los ataques de Speilbergen en los años 1610 y l'Hermite y Schapenham en los años de 1620, pero también debido a la caída en los ingresos de la minería del oro en Quito, la política de no estimular los asentamientos en el área permaneció estática. Esta posición, practicada también a lo largo de la costa oeste de la Nueva España, como lo muestra Peter Gerhard, era la única respuesta posible a la agresión extranjera, dada la extensión de la desprotegida línea costera. ${ }^{12}$ Se pensaba que debido a los grandes costos de defensa, el valor comercial de un nuevo pueblo portuario era demasiado alto.

9 Los diferentes poblados afro-indígenas de Esmeraldas fueron apodados «república zambo* por John Leddy Phelan, en Tiie Kingdom of Quito in the Seventeenth Century: Bureaucratic Politics in the Spanish Empire, Madison, Universitiy of Wisconsin Press, 1967.

10 Encuadernado como libramientos, Quito, 17 de Septiembre de 1598, Archivo Nacional de Historia, Quito (de ahora en adelante ANHQ) Real Hacienda, caja 37, folio 28v. El corsario isabelino Richard Hawkias, en sus Observations of Sir Richard Hawkins, Knight, or Voyage into the South Sea. Nueva York, Da Capo Press, 1968 [ed. facsímil de 1622], Pág. 124, menciona que conoció a Yllescas, a quién llama el «jefe molato» escogido de los Indígenas, en 1594 cerca a Bahía San Mateo.

11 Phelan, The Kindom of Quito, Pág. 12 
A pesar de la desaprobación oficial, los asientos mineros en ia región de Barbacoas continuaban despertando el interés de diversos sectores, tanto por la promoción militar que los servicios allí podían significar, como por la posibilidad de obtener oro. Hacia 1620 los soldados, sus familias, los esclavos y los indios de encomienda, habían comenzado a explotar los innumerables ríos de las tierras bajas de la provincia y a patrullar la costa que recién habían reconquistado. Los indígenas opusieron gran resistencia, pero el tiempo y la constancia hicieron que los españoles consiguieran hacia 1630 el objetivo de controlar los principales campos mineros y las zonas fluviales de la región. Ninguno de los grupos costeros se adaptó a la servidumbre de los españoles y mientras que en 1630 se habían contado aproximadamente unos dos mil indígenas, dos generaciones después sólo quedaba una fracción de dicho número, pues muchos de ellos sucumbieron por los abusos de los extranjeros y por las enfermedades. Luis Calero, citando una visita hecha en 1691 por el gobernador de Popayán, sostuvo que en toda la región de Las Barbacoas había 452 indígenas tributarios. Una epidemia de sarampión recorrió la Audiencia de Quito entre 1692-93 y aniquiló casi por completo a estos sobrevivientes, de tal forma que en el año de 1700 tan sólo quedaban 168 indígenas tributarios, algunos de ellos provenientes de las tierras altas circundantes, desde donde habían sido forzados a ir al área, a pesar de las normas que prohibían este tipo de desplazamientos. ${ }^{13}$ A finales del siglo XVII los minero-encomenderos de las Barbacoas asaltaron las poblaciones afro-indígenas de Esmeraldas, para capturar a los indios cimarrones de las Barbacoas que habían huido buscando refugio allí y para esclavizar a los indómitos afro-indígenas que vivían en libertad. Fue durante esta época que comenzaron a circular rumores según los cuales los piratas ingleses y franceses cruzaban el istmo cerca a Panamá y robaban barcos anclados en el Pacífico.

Si en 1680 los bucaneros hubieran atacado los campos mineros de Las Barbacoas, habrían encontrado, a más de oro, un gran número de esclavos africanos. Como lo habían aprendido en el Caribe, los esclavos, si no servían para desempeñar oficios en los barcos o como espías e intérpretes, podían venderse en otras partes, generalmente a comerciantes españoles inescrupulosos. En el caso de Las Barbacoas la disminución de la población indígena fue compensada de inmediato con la entrada forzosa

Gerhard, Pirates on the West Coast of New Spain, Págs. 24142. Tanto Phelan como Gerhard sugieren que esta política contraria al fomento de los asentamientos a lo largo de toda la cosa Pacífica de la América española sembró las semillas para un futuro subdesarrollo.

13 Un cura jesuita que ejercía sus actividades en la región desde 1630, Francisco Rugí, reclamaba en 1645 que había convertido a 1.900 indígenas al cristianismo, ver Autos «No 36», 1695 (no se da mes ni año, contiene copias de documentos hasta 1632), ANHQ Popayán, caja 14, f.7v. Estas cifras se amplían de acuerdo con un cálculo hecho en 1Ó35, según el cual había aproximadamente 1.000 indígenas, véase Lt. Govemador Lorenzo Villaquiram, en Pilar Ponte lava, ed, Relaciones Histórico-Geográficas déla Audiencia de Quito (Siglo XVI-XIX), 2 vols. Madrid: CSIC, 1991-92 (reimpreso Quito: Abya-Yala, 1993), T. 2, Pág- 205. Para la visita de 1691, ver Luis Calero, «Pasto, 1535-1700: The Social and Economic Decline of Indian Communities in the Southern Colombian Andes», Ph.D diss., Universityof California at Berkeley, 1988, Pág. 318-19- La cifra del año de 1700 fue tomada de un censo o numeración que se incluye en los Autos contra Doña Manuela Godoy. 11 de Octubre de 1700, ANHQ, Indígenas, caja 24, f.25v. Para una descripción de las epidemias de comienzos de 1690, ver Suzanne Austin Alchon, Native Socieiy and Visease in Colonial Ecuador, Cambridge, Cambridge University Press, 1991, Pág. 91-99- 
de negros africanos. Ellos, al igual que los indígenas que los precedieron, no fueron dóciles. Muchos huyeron hacia los bosques en forma temporal o para establecer comunidades cimarronas fuera del control de los españoles. De otra parte, los esclavos que permanecieron en cautiverio representaron una constante amenaza, ya que su número sobrepasaba al de sus amos por un amplio margen. En su mayoría eran bozales, un término degradante que se utilizaba para denominar a los negros recién llegados del África y a quienes se les consideraba inclinados a la rebelión violenta. A largo plazo, los bucaneros representaban una amenaza eventual, en comparación al potencial explosivo que podían representar las revueltas de esclavos e indígenas. Este hecho siempre fue tenido en cuenta por los amos españoles de la provincia. ${ }^{14} \mathrm{El}$ enemigo interno causaba preocupación, ya que un ataque pirata en pequeña escala podía generar fácilmente a una rebelión popular a grande escala. En Panamá y otras regiones los esclavos e indígenas cimarrones, desde los tiempos de Drake, habían ayudado siempre y voluntariamente a los invasores extranjeros.

A finales del siglo XVII las increíbles leyendas acerca de los daños causados por los ataques piratas, sobre todo en los puertos caribeños de la Habana, Santa Marta, Cartagena y Portobelo, se habían convertido en hechos corrientes para la Audiencia. de Quito. En Quito y en otras ciudades del interior del Perú circulaban rumores sobre la amenaza de los piratas en el Caribe. Estas noticias se usaban con el fin de forzar el pago de los situados, donativos e impuestos de guerra que se necesitaban para habilitar los escuadrones navales y para mantener las guarniciones del Imperio. ${ }^{15}$ Con la llegada, de Sharp y sus seguidores al Pacífico español en 1680 estos rumores se convertirían en realidad. Algunos ciudadanos de Las Barbacoas ya habían visto lo que los bucaneros eran capaces de hacer. Ellos habían navegado hacia el norte en 1671 para ayudar a Panamá contra Henry Morgan. Un barco que condujo a Bartolomé Estupiñán y Flores, un propietario local de minas y veterano de batallas navales en el Mediterráneo y en el Atlántico oriental, había arribado demasiado tarde para participar en la defensa de Panamá, pero los recuerdos de la destrucción de esta ciudad y la leyenda de lo ocurrido en el Caribe, fue lo que hizo que los mineros de la Barbacoas comenzaran a pensar en su propia protección.

14 Véase la caja real de Barbacoas, 1683-85, Archivo Central del Cauca (Popayán, de ahora en adelante ACC) Signatura 1099, ff, 1 3v, lista de 28 minas de oro en Barbacoas en 1684. En los Autos contra Doña Manuela Godoy (ANHQ), f.22v. el procurador de Santa Maña del Puerto, Francisco Prado Zúñiga, resumió los temores locales en los siguientes términos: "...los ánimos de los vecinos son tan cortos en el número de los que viven en esa ciudad y tan pusilánimes que no podran tener resistencia a una conjuración o conspiración que hagan los d[ic]hos yndios y mulatos como lo an echo en Cartagena y otras ciudades es constante que no uviera ningún seguro de qualquiera traición que quieran intentar...».

15 Ver, por ejemplo, los Autos en Pírate Enemy, Cartagena, 1674, ANHQ Popayán, caja 5. En este informe se hace referencia a la captura de una fragata fuera de Santa Marta, en el Caribe, por un bucanero inglés llamado Juan Preñas. Tres navegantes y un piloto afirmaban que sus captores piratas eran de varias naciones, incluyendo franceses, portugueses, españoles c ingleses. Según el bucanero Raveneau de Lussan, quién participó en el saqueo de Guayaquil de 1687, los curas locales habían convencidoa los feligreses de que los bucaneros eran cánsales. Ver Marguerite E. Wilbur, Raveneau de Lussan: Buccaneer of the Spanish Main and Early French Filibuster of the Pacific, Cleveland, Arthur H. Clark, 1929, Pág. 211. 
El primer encuentro ocurrió cuando algunos de los bucaneros atracaron junto a la boca del río Patía en agosto de 1680. Ellos viajaban en una pequeña embarcación e intentaban llegar hasta donde Bartholomew Sharp, después de haberse separado de él cerca de Panamá. Ringrose y Sharp acababan de dejar la Isla de Gorgona para establecerse en otro punto en donde carenar y aprovisionar los barcos. El punto elegido fue la Isla de la Plata o la Isla de Drake y fue por esto por lo que sus colegas no los encontraron. Tal y como lo reconoce Ringrose en su Diario y en sus notas de la Carta de Navegación, un grupo de ocho ingleses, dirigidos por Edward Dolman (o Doleman), lograron capturar algunos prisioneros a lo largo de la costa antes de introducirse en la Isla del Gallo. Ellos presionaron a sus cautivos, incluyendo por lo menos a un indígena y a varias mujeres, para obtener información acerca de las defensas locales, antes de capturar una canoa o balsa indígena, en la que luego remaron hasta el cercano puerto de Tumaco. ${ }^{17}$

Fue aquí, en Tumaco, de acuerdo con el informe oficial de la Corona preparado por el virrey peruano, Liñán y Cisneros, que los piratas recibieron el «justo castigo a su atrevimiento». ${ }^{18}$ Siete de los ocho ingleses fueron muertos en una emboscada dirigida por un minero y encomendero local llamado Juan Godoy y Prado. El y un grupo de compañeros se escondieron entre los arbustos, anticipando la llegada a tierra de los piratas, y luego salieron para dispararles con sus escopetas. De acuerdo con un manuscrito enviado a la audiencia de Quito por el superintendente local de amias, Bartolomé Estupiñán y Flores, Godoy y sus ayudantes, probablemente esclavos e indígenas anónimos, habían derrotado fácilmente a los «corsarios enemigos» en Tumaco. Por su lado, Estupiñán organizó una misión de reconocimiento a la Isla Gorgona en busca de los bucaneros que quedaban, pero sólo encontró rastros de sus campamentos. Esta acción defensiva, uno de los pocos casos en que la llegada a tierra de los bucaneros fue aniquilada instantáneamente, tuvo un impacto duradero sobre los posteriores proyectos defensivos de la región. El único sobreviviente del ataque sorpresa, un tal Carlos Alem (tal vez Charles Alien), le dijo a sus captores que su grupo había sido enviado con el fin de reconocer la costa y que después debía reunirse con otro grupo más grande frente a Guayaquil. Muy pronto Sharp y su gente supieron por los prisioneros capturados frente a Guayaquil, que sus planes eran conocidos por los españoles y procedieron a alterar su ruta. ${ }^{19}$

16 Petición para devolver cuatro indígenas de encomienda, Bartolomé Estupiñán y Flores, 1683, ANHQ, Popayán, caja 8, ff. 49-50.

17 Ringrose registra el incidente de la Isla Gallo tanto en su periódico (Esquemeling. The Buccaneers of America, 361), como en sus notas marítimas (Derek Howse y Nomwi Tlrowen eds., A Buccaneer's Atlas: Basil Ringrose's South Sea Waggoner, Berkeley, University of California Press, 1992, Págs. 138 y 140.

18 El incidente se encuentra en Manuel A. Fuentes, ed.. Memorias de los virreyes que han gobernado el Perú, 6 vols., lima, Felipe Bailly, 1859, T. I, Págs. 331-32. El escrito dice textualmente: "...volvieron al mar llevando algunos prisioneros para servirse de sus noticias y habiendo apresado el barco de unos Indios, de aquellos puertas arribaron otra vez al de Tumaco, experimentaron allí el justo castigo a su atrevimiento...». Véase también el Libro de Tanteos, 1677-1714, ANHQ Real Hacienda, caja 42, ff. 33 - 36.

19 Esquemeling, The Buccaneers of America, Pág. 36l, Fuentes, Memorias de las Virreyes, 332. También ver ANHQ Popayán caja 8, $1683, f f .58 v-59$. 
El ataque sobre el grupo de Dolman fue mucho más importante para los españoles que para los bucaneros. Gentes de la región, sin recibir pago alguno, habían logrado derrotar a una fuerza enemiga. El que ésta fuera pequeña no disminuía la importancia del hecho para el bando español. Ringrose reclamaba después, sin evidencias de primera mano, que los ingleses habían sido superados en número de diez a uno, mientras que las gentes de Las Barbacoas y el virrey peruano reclamaban que había existido el mismo número de combatientes. ${ }^{20}$ A pesar del equilibrio se había establecido un precedente importante. De hecho hasta bien entrado el siglo XVIII se invitó a los residentes de todos los colores de Las Barbacoas a que tomaran parte en misiones defensivas. Otros, incluidos los mulatos libres, recibirían títulos militares y honores similares a cambio de sus servicios a la vuelta del siglo $\mathrm{XVIII}^{21}$ Muy pronto cada uno de los encomenderos de la provincia estaba pidiendo a la Audiencia de Quito un reconocimiento formal por sus servicios contra los invasores. Cada dueño de esclavos, así como los propietarios de las minas, eran posibles maestres de campo o «maestro de campo», un rango que muchos adquirían a pesar de la escasez evidente de batallas. Otros utilizaron la amenaza que suponían los piratas con fines negativos, denunciando a sus rivales como cobardes por no participar en ejercicios defensivos o por ceder ante las demandas de los piratas. Algunos miembros de las élites, como el Sargento Mayor Juan de Godoy y Prado, comandante de los escopeteros en la emboscada de 1680, y el Superintendente de armas Bartolomé Estupiñán y Flores, utilizando la amenaza que suponían los piratas como trampolín para obtener distinción local, convirtiéndose en caudillos al autoproclamar su importancia, tanto en la defensa de la costa, como en la explotación de las riquezas de la región. ${ }^{22}$

Sin embargo, las élites españolas y la gente libre de color no fueron las únicas beneficiadas con el temor por los piratas que recorría la región a fines del siglo XVII. Los indígenas cuasi-independientes, como los Cayapas de las zonas altas de Esmeraldas y de los afluentes del río Santiago (hoy en día Ecuador), igualmente reclamaban haber servido a la Corona contra el enemigo. En 1679 los Cayapas pidieron que la Audiencia de Quito los protegiera del gobernador titular de la provincia de Esmeraldas, Nicolás de Andagoya, quién buscó reasentar a muchos de ellos cerca a los pueblos afro-indígenas de San Mateo y Atacames. Los indígenas reclamaban que este reasentamiento iría en contra de las necesidades defensivas de

20 Howse and Thrower; A Buccaneer’s Atlas, Pág. 138, Fuentes, Memorias de los Virreyes, Pág. 331.

21 Se organizaron compañías de mulatos libres y montañeses en las Balbacoas antes de 1709; ver Barbacoas, prorrata de 1709, ANHQ Popayán, folder de «1710», aja 35.

22 Por ejemplo, se reclamaron los servicios prestados en la defensa contra los piratas en los siguientes casos: petición por una licencia para posada, Sargento Mayor Diego Miguel Fernández de Oviedo de Pasto, junio 14 de 1688, ANHQ Popayán, caja 10, f.2v; apelación de pérdida de la encomienda, Baltasar Giysedo Salazar, 1687, ANHQ,, Popayán, caja 9, f.2; cacique de Coaiquer vs. Alejandro Maldonado de Gamboa, por vivir en dicho pueblo (este último reclamó que la amenaza pirata justificaba su residencia en el lugar), 1681, ANHQ Popayán, caja 8, f. 21; apelación del Maestre de Campo Lucas Femández de Oviedo, quién intentó eludir el pleito que le entabló su esposa, reclamando que su presencia en la costa era necesaria para combatir a los piratas, 1689, ANHQ Popayán, caj 10, f.2. 
la Corona, puesto que ellos se encontraban muy bien situados para informar a los oficiales acerca de barcos sospechosos y desembarcos de enemigos. En realidad, ellos sólo habían participado recientemente en la defensa de Panamá (1671), acompañando a un grupo de soldados de Ibarra, armados con dardos, flechas y escopetas. Arguyeron, apoyados por el testimonio de un fraile mercedario que residía en el área, que a ellos no se les debería trasladar por razones de seguridad estatal. El gobernador sostuvo que este era un argumento oportunista y que los Cayapas no habían hecho nada de importancia por combatir a los piratas. Sostuvo que él los necesitaba para que los colonos españoles de la costa pudieran estar mejor atendidos. Sin embargo, la Audiencia se puso del lado de los Cayapas. ${ }^{23}$

Los afro-indígenas de la costa de las Esmeraldas también pidieron que se les reconociera la importancia que tenían como centinelas. Desde el año de 1667, cuando sólo circulaban rumores sobre los piratas, y hasta comienzos del siglo XVIII, los caciques de San Mateo y Atacama denunciaron que los encomenderos de Las Barbacoas estaban sacando naturales a la fuerza para llevarlos a cortar madera cerca a Tumaco y para trabajar en las minas de oro del delta del alto Patía. Estos encomenderos habían secuestrado a muchos jóvenes, que morían víctimas de malos tratos y de enfermedades, de tal manera que los pueblos estaban a punto de sufrir un colapso demográfico. Los caciques alegaban que esto no sólo sería trágico para la gente de Esmeraldas, sino que también significaba un gran riesgo para la Corona, ya que el desembarco de piratas no podría detectarse eficazmente y mucho menos podrían ser repelidos. ${ }^{24} \mathrm{Sin}$ embargo, los reclamos por parte de los caciques sobre su papel en el sistema de defensa de los españoles eran, en cierta, forma exagerados. Como Ringrose lo anotó después, en 1680, los habitantes afro-indígenas de las Esmeraldas vendían rutinariamente provisiones a los bucaneros, poniéndolas en San Mateo. Evidentemente, ellos no fueron muy amigos de los piratas, pero tampoco valoraban negativamente el aprovecharse del contrabando. ${ }^{25} \mathrm{Al}$ comienzo la Audiencia, pensó en retirar a los Esmeraldeños, para terminar mirándolos con desconfianza. ${ }^{26}$ La nueva amena-

Cacique Don Francisco Napa vs. Gobernador Nicolás de Andagoya, julio 28 de 1679, ANHQ Indígenas, caja 12, f. 4. Según el testimonio del fraile mercedario Antonio Ruiz de Alvarado, el texto de la determinación de la Audiencia fue el siguiente: «.. .estén en sentenela para que en las ocasiones que yntentaren los enemigos yngleses u otros que quieran entrar por dicho puerto den aviso al corregidor de la villa de san miguel de ybarra como lo hiaeron en la ocasión pasada que ynbadieron a la ciudad de panamá los yngleses acudieron los dichos yndios a la defensa de d[ic]ho puerto faumentando a los españoles soldados que remitió el dliclho corregidor de la villa a quienes les socorrió con la comida y asistieron así con escopetas como con dardos y flechas...».

24 Petición del cacique de Esmeraldas..., 1667, ANHQEsclavas, caj 1.

25 Ver Howse y Thrower, A Buccaneers Adas, Pág. 143. Ringrose señaló: «The Bay of St Matheo... is posest by Indian warriours (who will huit no strainger) \& here is sold by the Mullat's [i.e. Afro-Indians] all sorts of provissions. But I give you a Caution of 2 things wbich are of great importance Vlzt lst not to Jest with there [sic] women or debuch them; 2ndly not to threaten the natives; with armes or otherwise but treat them with humility you may have what you please.».

26 Petición del cacique de Esmeraldas, f.3, y encuadernado como tanteos, 1677-1714, ANHQ Real Hacienda, caja 42, f. 19. El primer documento menciona a soldados enviados a Esmeraldas en el año de 1684, tanto para buscar piratas, como para que «...contengan y repriman a los yndios mulatos [afro-indígenas] en la ynfieldad y desconfiansa que reconosieren...». 
za pirata le dio a los grupos indígenas de la costa una nueva oportunidad de conseguir como en el pasado una autonomía relativa. Como en la época de Drake y Hawkin, la Audiencia, al no pagar un ejército pemianente, se vio forzada a comprometerse con la política de posponer la conquista total de la región.

Con esto no se pretende sugerir que la Audiencia no hubiera gastado dinero combatiendo a los piratas. Cada libro de cuentas de la tesorería real de Quito menciona, desde los años de 1670 hasta los de 1690, algún nuevo gasto relacionado con la defensa costera. Los soldados de la costa, desde el Patía hasta Panamá, pidieron armas, pólvora y municiones, al igual que otra variedad de provisiones, algunas a crédito y otras pagadas por la. Real Hacienda. Los oficiales del ejército en Las Barbacoas reclamaban que las provisiones de pólvora no sólo se gastaban combatiendo a los piratas, sino que también muchas provisiones se dañaban debido a la humedad del clima. ${ }^{27}$ Dada la urgencia de estas solicitudes, la Audiencia se apresuró a entregar la mayor cantidad, posible de pólvora. Aunque la fábrica de pólvora de Latacunga, un pequeño pueblo localizado en las zonas montañosas, a tan sólo noventa kilómetros al sur de Quito, estaba funcionando a plena capacidad, se hizo un mayor esfuerzo para satisfacer la demanda, sobretodo después de 1670, arando las solicitudes que se hacían desde Panamá excedieron la oferta. La Audiencia propuso en 1680 cuadruplicarla producción, incrementándola de 4.000 a 15.000 libras por año. ${ }^{28} \mathrm{~A}$ más de asumir los costos de las provisiones, la Audiencia también comenzó a pagar salarios a los soldados. En 1684 los oidores votaron para equipar una pequeña fuerza expedicionaria que, después de abrirse paso desde los Andes, reconociera la costa de Esmeraldas. Un grupo similar salió de la ciudad de Ibarra a comienzos del año $1685 .{ }^{29} \mathrm{La}$ defensa contra los piratas se había convertido en una empresa muy costosa (y para algunos lucrativa).

A pesar de tanta agitación, el primer ataque de los bucaneros a los pueblos de la costa de la Audiencia de Quito fue más bien moderado. Temerosos de haber perdido el elemento sorpresa en Guayaquil, los invasores ingleses, bajo las órdenes de Bartholomew Sharp, prefirieron intentar la captura de un barco cargado con plata de Potosí. Ninguna nave con metales apareció y los bucaneros sólo lograron dominar unas cuantas embarcaciones que llevaban telas ordinarias de lana de Quito, vino,

27 Visita de Quito real caja, Enero 7 de 1686, ANHQ, Real Hacienda, caja 5, ff. 47v-49. La audiencia estuvo de acuerdo en enviar 4.000 balas, 1 quintal de fusiles y 477 libras de pólvora valorada en 1.000 pesos de plata. Se le expidió recito a la Gobernación de Popayán por este material.

28 Libro de junta e Hacienda Real, 23 de Mayo de 1680. ANHQ Real Hacienda, caja 42, tí. 2-3. Se propusieron mejoras en cuanto a la organización del trabajo, la estructura de la planta, provisión de ingredientes y empaquetamiento. Los peones indígenas debían realizar varias tareas, junto con criminales convictas y vagabundos. El precio oficial de la pólvora aumentó de 2 reales la libra a 3 en el año de 1684 (.Visita de Quito real caja, 17 de Mayo de 1684, ANHQ Real Hacienda, caja 5, f.4v).

29 Visita de Quito real caja, 24 de Abril de 1684, ANHQ, Real Hacienda, caja 5, ff. 48-49. Desde Quito se enviaron doce hombres, bajo la dirección del Capitán Nicolás Arguello, para que reconocieran Punta Manglares (cerca a la boca del Mira y a Tumaco) hasta Cato Pasado. El contingente de Ibarra estaba dirigido por el Maestre de Campo Josef de Recalde y Aguirre. 
madera y esclavos. El fracaso los llevó casi que a un amotinamiento, pero durante los nueve meses siguientes la banda de Sharp, compuesta por aproximadamente 150 piratas, llevó a cabo exitosas invasiones a Ilo, Coquimbo y La Serena, en las costas del sur del Perú y de Chile. Un intento de asalto hecho en Arica fracasó. Más de cuarenta bucaneros murieron durante el enfrentamiento con los vecinos de esa población, quienes estaban muy bien preparados. Después de esta decepción, más de la mitad del llamado «Grupo de Alegres Muchahos» se separó en la Isla de la Plata. ${ }^{30}$ En abril de 1681 un grupo que incluía a los escritores de los Diarios Lionel Wafer y William Dampier, se dirigió hacia el norte, para cruzar el istmo de Panamá, pero Sharp, Ringrose y setenta compañeros continuaron atacando el Pacífico español. En sus últimas aventuras Sharp y Ringrose tuvieron un golpe de suerte que los haría más famosos que el haber tomado galeones con tesoros. Este fue la captura de un libro español de cartas de marear o derrotero del Rosario, tomado frente a Cabo Pasado (jurisdicción de Quito) el 29 de julio de 1681. Este «carretero», como lo llamaban los ingleses, fue copiado después por el explorador y cartógrafo William Hack, y traducido y entregado a los ministros de Carlos II con gran pompa y ceremonial. De hecho, las cartas de marear, junto con sus detallados Diarios, contribuyeron a salvar de la horca a los bucaneros cuando fueron acusados de piratería, asesinato y diversos ultrajes, después de retornar a Inglaterra a mediados de $1682 .{ }^{31}$

Sin embargo, mientras que Sharp y Ringrose se hallaban en el Pacífico español, el "carretero" valía muy poco. A mediados de 1681 los bucaneros ya habían estado en casi todos los sitios señalados en estos mapas y en algunos casos conocían mejor el litoral costero que los mismos cartógrafos. Utilizando sus viejas habilidades para navegar bajo la bruma y siguiendo las observaciones celestes, los piratas tenían muy poca necesidad del libro de cartas de marear. Si el "derrotero" hubiera señalado algún tesoro que se encontrará tierra adentro o si Sharp hubiera dirigido una fuerza de desembarco y una flota muy grande, entonces hubiera sido una herramienta muy valiosa e importante. En cambio, la vaguedad, las omisiones y los errores de las cartas de marear fueron de gran ayuda para los españoles, pues de hecho estaban diseñadas para que no dieran mucha información si caían en manos enemigas. Como puede verse en los mapas que dibujaban Las Barbacoas y sus alrededores, las minas no se indicaban y los ríos estaban en lugares equivocados o con nombres diferentes. Parece intencional el hecho de que las cartas de marear posean tan pocos detalles en cuanto a las rutas comerciales del interior, hasta el punto de excluir pueblos importantes cercanos como Santa María del Puerto (ver mapas 1 y 2 ). ${ }^{32}$

\footnotetext{
Philip Ayres (1684), citado en Bradley, 77?e Lure of Peru, 108

31 Una cronología de las actividades de Sharp (incluyendo sus juicios) está en Howse and Thrower, A Buccaneer's Atlas, apéndice C; también ver Bradley, The Lure of Peru, 112-21.

32 Los cuadros de las Barbacoas aparecen en Howse and Thrower, A Bucameer's Atlas, 137,139. Un moderno mapa que muestra las localidades próximas a los campos de oro coloniales está en Rotert C. West. Colonial Placer Mining in Colombia, Pág. 18.
} 
MAPA 1

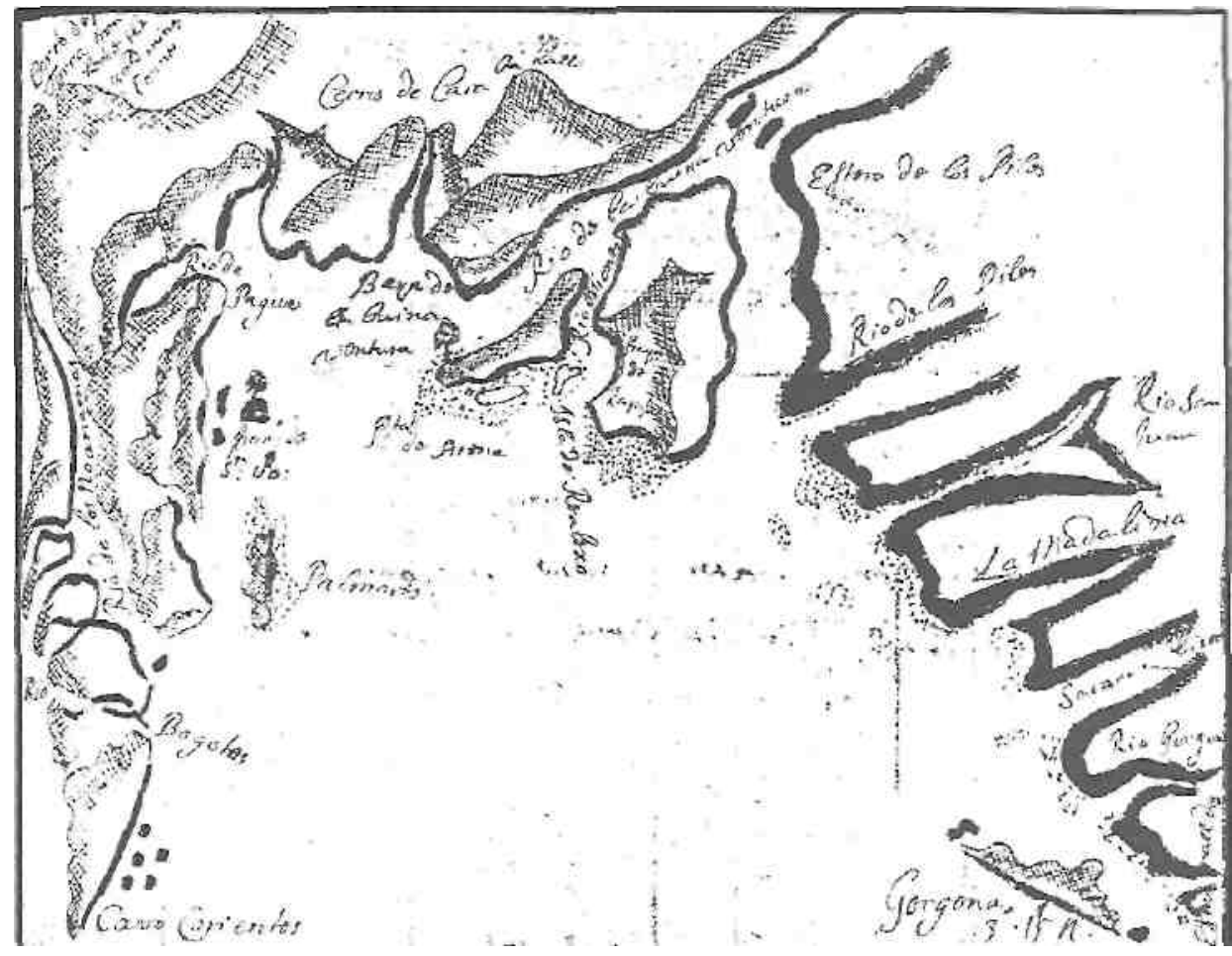

El Caro de Torravicne desde aqui y desde las minas de oro-

Isla de Realezo

n. 100 (Mapa 47).

? Cerro de Guaba Hall

Cavo Corientes

Rio Astiones

Baya de Raposa

Estero de los Piles

Rio Bogotes= Río Baudo, 100 millas de largo $(160 \mathrm{Km})$

Rio de los Piles

Rio de los Noanamas= Río San Juan, 200 millas de largo (320 $\mathrm{Km}$ ), la mayor parte de su trayecto es navegable, con ricas placeres de oro en las partes altas (departamento de Caldas) en la Cordillera Occidental. El primer reconocimiento de la costa Pacífica de Sur América, fue realizado por Pascual de Andagoya en 1522 desde Panamá, quién alcanzó el Río San Juan (415'N), límite norte del Imperio Inca.

Palmares = Isla Palmas

ffranxie Sn Po:

\section{Rio de Pagua}

Baya dé la Buina ventura = Bahía Buenaventura («buenaventura» (good fortune))-el puerto colombiano más grande del Pacífico.

Río de la buina ventura =Río Buenaventura

Rio San Juan

La Madalina ? Sarambria

Rio Gorgon

Esmiralldos

Gorgona =Isla Gorgona. Francisco Pizarro esperó durante casi siete meses, entre 1526 - 27, en la Isla Gorgona a Diego de Almagro para regresar desde Panamá con refuerzos. Hack f. 57: "El capitán Sharpe la llamó Gorgona después de que se estableció alli. Esta isla está completamente poblada con árboles del tipo María: los cuales son muy útiles para hacer mástiles de las embarcaciones y en la paite sureste de ella hay un río de muy buenasaguas

*3.15'N- Latitud 2 58'N.

Pta de Arena 
MAPA 2

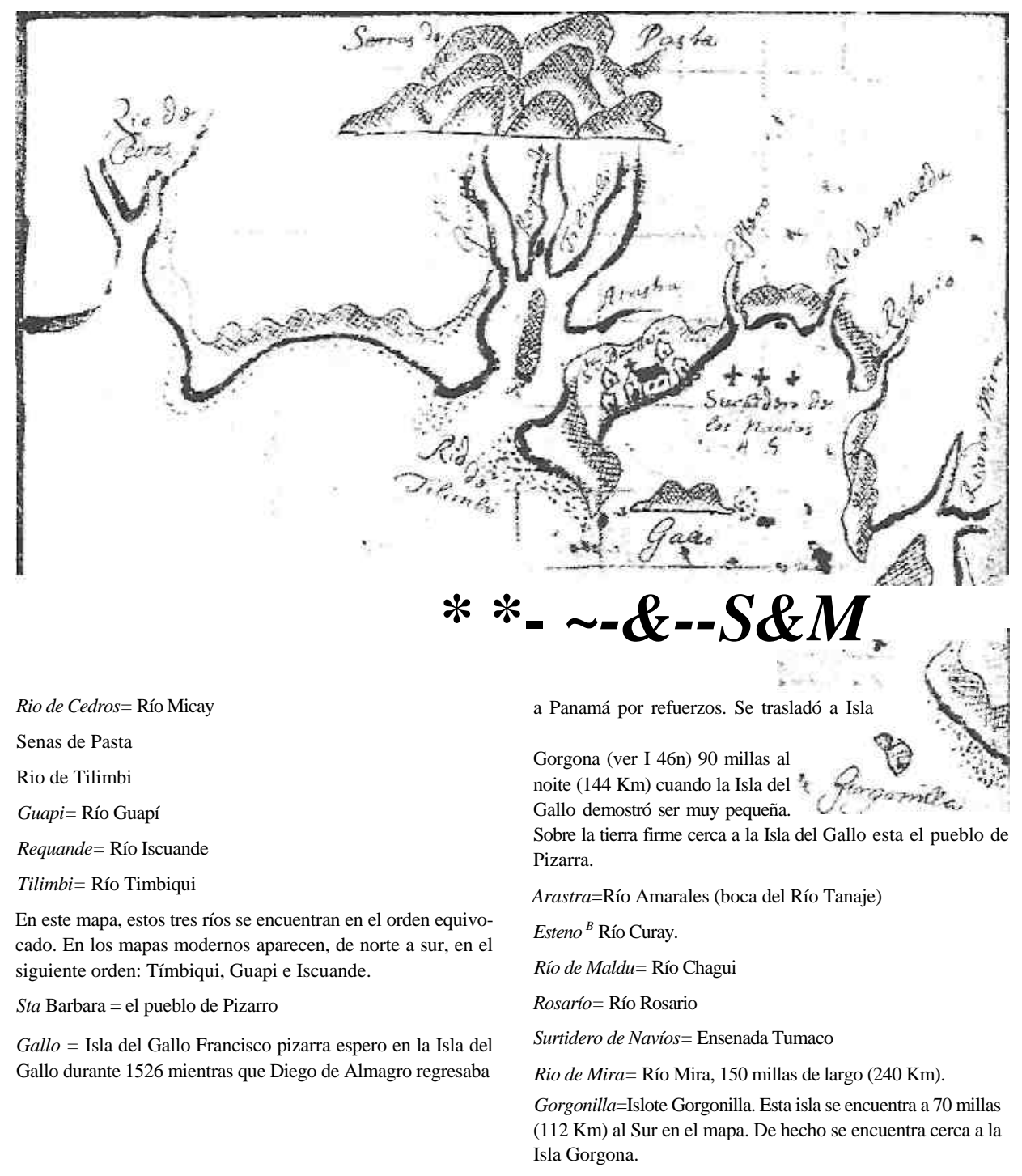

La reproducción de los Mapas 1 y $\mathbf{2}$ fue hecha con permiso de la imprenta de la Universidad de California, y tomada de: Derek Howse y Norman J.Thorower, A Buccaneer's Atlas. A Ringroses' South Sea Waggoner (A sea atlas and sailing directions of the Pacific Coast of the Americas), 1682, Berkeley: University of California Press, 1992. 
Fue una estratagema inteligente haber capturado al "derrotero", pero éste fue de poca ayuda para el siguiente grupo de bucaneros, compuesto sobre todo por un enorme y variado conglomerado de ingleses y franceses. Entre los primeros estaban veteranos invasores de la banda de Sharp, como eran Dampier y Wafer, que navegaban esta vez hacia el mar del sur, vía el estrecho de Magallanes, en un bajel danés robado, que llamaban Bachelors Delight. Estos bucaneros, bajo la dirección de un tal Capitán Davis de Virginia, posiblemente se encontraron frente a la costa de Chile con dos barcos ingleses de contrabando, a comienzos de 1684. Uno de ellos se llamaba Nicholas y estaba bajo el mando de Thomas Eaton, el otro, el Cygnet, al mando de Charles Swan. En el Cygnet también estaba Basil Ringrose, quien había convencido a un grupo de inversionistas londinenses que era posible practicar el contrabando de mercancías en el mar del Sur, en forma pacífica. Sin embargo Ringrose estaba equivocado. Después de varias negativas para negociar en puertos chilenos, Swan y Ringrose siguieron a Eaton para unirse a los bucaneros. ${ }^{33}$ Un sinnúmero de intentos para capturar galeones cargados de plata frente a Arica y Callao fracasaron, y después de una decepcionante invasión a Paita y unos frustrantes intentos en Guayaquil, Swan, Dampier y sus compañeros intentaron un ataque sorpresa a Tumaco, puerto y puerta de entrada a los campos mineros de Barbacoas. El 28 de diciembre de 1684, sin mayor esfuerzo, se apoderaron de Tumaco y tomaron por rehenes a sus habitantes.

Para los bucaneros este asalto no valía la pena ni mencionarlo, pero desde la perspectiva española fue un evento importante por sus múltiples repercusiones. Los testimonios que relatan este acontecimiento sugieren que los habitantes de la provincia de Las Barbacoas temían una invasión a gran escala de sus centros mineros. El incidente de Tumaco se planeó después de que los bucaneros capturaran unos 320 esclavos y un cargamento de telas frente a Guayaquil. Pidieron un rescate por este cargamento, pero se les negó y decidieron navegar hacia el norte en busca de revancha. Los bucaneros establecieron una base temporal a lo largo del río Santiago, cerca del hoy en día llamado San Lorenzo, Ecuador. Aquí vieron a algunos indígenas, probablemente del grupo de los Cayapas, quienes los evitaron y desaparecieron río arriba. Entonces los bucaneros se dirigieron hacia Tumaco en canoas y en el camino capturaron a un indígena, a quien forzaron para que les sirviera de guía. ${ }^{34}$ Según un informe enviado a Quito, más de sesenta piratas llegaron a Tumaco a medianoche y tomaron como rehenes a un sinnúmero de vecinos importantes y a sus sirvientes mientras dormían. Sin embargo, ninguno de los españoles cautivos habló, por lo que los piratas colocaron una cuerda alrededor del cuello de un indio de encomienda y lo presionaron para

33 Bradley, The Lure of Peru, Págs. 131-35.

34 William Dampier, A New Voyage Around the World, Londres, Adam y Charles Black, 1937 (1697), Págs. 121-22. 
obtener información. Querían saber qué había río arriba y qué tan lejos estaba el pueblo de Pasto, un objetivo muy distante y poco accesible en los Andes para un grupo de intrusos extranjeros, que sumaba menos de 200 y cuyo camino no sabían cómo lo defendían. ${ }^{35}$

El prisionero indígena rehusó hablar y de inmediato fue ahorcado, lo cual produjo un gran temor entre los otros prisioneros en Tumaco. Los piratas fueron claros al manifestar que lo único que les interesaba eran los negocios. A más de esta brutal ejecución, también habían asesinado a un mulato esclavo y a un español de la localidad por haber intentado alertar al pueblo del ataque. Luego, su atención se centró en un importante vecino, Sebastián Fernández de Briones, propietario de un barco. Fernández satisfizo las preguntas de los bucaneros, después de que lo encañonaron y lo amenazaron con hacerlo volar en dos pedazos. ${ }^{36}$ Como no les interesaba hacer ostentación de sus crueldades, piratas como Dampier y Wafer nunca hicieron mención en sus Diarios sobre esta clase de terrorismo. Sin embargo, los Diarios si sugieren que eran conscientes de la cercanía de los placeres de minas de Las Barbacoas y los querían encontrar. Como afirma Dampier:

"Esta villa de Tomaco no es mas que pequeña y se encuentra localizada no muy lejos de la Boca del Río. Es un sitio para entretener a los comerciantes españoles que vienen a Gallo para cargar madera o para traficar con los indígenas por oro... El día 31 dos de nuestras canoas, que se encontraban arriba del río Tomaco, regresaron nuevamente al pueblo. Habían remado siete u ocho leguas y solo encontraron una Casa Española, la cual según les contaron pertenecía a una señora que vivía en Lima; ella tenía aqui sirvientes que comerciaban con los indígenas por oro; pero al ver que venían hombres huyeron: Aún así nuestros hombres encontraron alli varias onzas de oro en calabazas." ${ }^{37}$

Después de aterrorizar a sus prisioneros, los bucaneros encontraron muy pocas cosas de interés, a pesar de que la distancia a los campos de oro de las Barbacoas era relativamente corta. Este fue un gran desacierto, si se considera que tenían rehenes y que el año anterior los placeres de oro del distrito habían registrado más de 20.000 castellanos de oro fino en la casa de fundición o fundición real de Santa María del Puerto. ${ }^{38}$ Parece que los prisioneros españoles y, lo que es aún más sorprendente, los indígenas y africanos a su cargo, no revelaron nada acerca de ello.

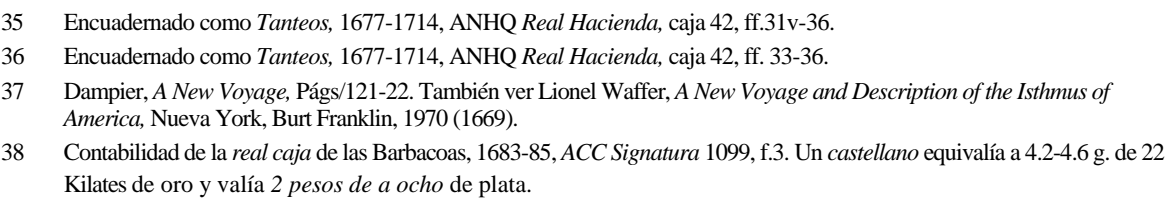


Después de un breve reconocimiento del área en canoas, los bucaneros abandonaron sus planes de invadir la región. ¿Por qué no buscaron las cercanas minas de oro que ellos sabían que existían? Primero, puede suponerse que, como otros grupos de ingleses y franceses que vinieron con intenciones similares, temían ser interceptados y asesinados, sobre todo después de crearles a los indios, africanos y españoles sentimientos de venganza por los desmanes cometidos en los ataques a Tumaco y sus alrededores. Al describir la región alrededor del río Santiago, desde donde los piratas habían lanzado el ataque a Tumaco, Dampier manifestó por qué se mantuvieron a distancia:

"...la bestialidad y enemistad de todos los nativos de esta costa, que están fortificados de forma natural por sus ríos y vastos bosques, desde donde con sus flechas pueden fácilmente molestar a cualquiera que llegue allí a asaltarlos....todo el país hasta ahora esta lleno de intransitables bosques; de tal forma que para llegar hasta donde los indígenas, o las minas y montañas, no hay forma de hacerlo sino remando río arriba." ${ }^{39}$

Por lo tanto, una combinación de obstáculos geográficos y humanos mantuvo a los bucaneros lejos de Las Barbacoas.

Tras oír acerca de las atrocidades de los piratas en Tumaco, los jueces de la Audiencia de Quito enviaron más soldados para que patrullaran la costa alrededor de Esmeraldas y para que cualquiera que fuesen las herramientas, municiones y bienes no perecederos, se compartiesen con los vecinos de las Barbacoas. También intentaron aprovisionar el crucial puerto de Guayaquil, en vano, como muy pronto se vería. Como lo muestran los libros de contabilidad de la Real Hacienda, la Audiencia realmente no se podía dar el lujo de defender su costa. Por ejemplo, en casi todos los asuntos, Quito reclamó la posesión de la Provincia de Las Barbacoas, a pesar de que técnicamente estaba en la jurisdicción de la vecina gobernación de Popayán. Quito quería controlar a Las Barbacoas porque era un mercado clave y una apreciada fuente de riqueza en oro y circulante. Sin embargo, al llegar al tema de la defensa, la Audiencia enviaba la cuenta de gastos a la real caja de Popayán, «a la cual jurisdicción dice que pertenece la provincia». ${ }^{40}$ Se esperaba que Guayaquil, mientras se encontrara en la jurisdicción de Quito, contribuyera a su propio fondo de defensa. Las élites mercantiles de este puerto, normalmente próspero, al haber sido forzadas a pagar numerosas cargas para la defensa, sólo podían ofrecerle al erario real una insignificante cantidad de granos de cacao a cambio de pólvora y otras provisiones. ${ }^{41}$

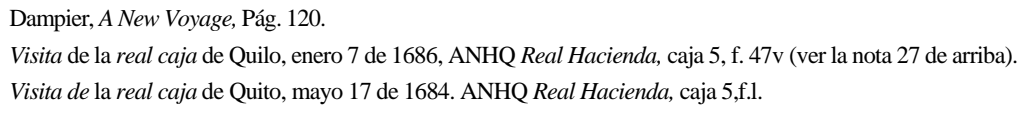


Quito se encontraba por la misma época envuelto en profundos problemas financieros. Cada año el situado a Cartagena le representaba más de 15.000 pesos, o sea una quinta parte del pequeño presupuesto de la Audiencia. Aún así, esta enorme remesa se quedaba corta frente a las demandas de la Corona. A mediados de 1690 Quito se encontraba atrasado en los pagos del situado, que se valoraba en 150.000 pesos, una suma impensable para una región pobre en dinero efectivo e ineficaz para recolectarlo. Después de leer otra de las frágiles explicaciones de la Audiencia en torno a su más reciente déficit presupuestal, un funcionario de la Hacienda virreinal en Lima contestó con exasperación: «...pues, en ninguna otra caja del reino [Perú] se experimenta atraso tan notorio...». ${ }^{42}$ Sin embargo, mientras que Quito luchaba por balancear sus libros de cuentas, los piratas continuaban creyendo que los ríos de la región estaban llenos de oro. Por ejemplo, Dampier a la vez que reconocía el importante comercio textil de Quito, estaba convencido de su riqueza mineral y describía el tercero como,

"...rodeado de montañas de una vasta altura, de cuyas entrañas han surgido grandes ríos. Estas montañas abundan en oro, el cual debido a las violentas lluvias es arrastrado con la harena hacia los arroyos adyacentes, donde los indígenas acuden en grupo, quitándole la arena y colocando el polvo de oro en sus calabazas o en la cáscaraa de los calabacines...aquí enfatizaré el hecho de que Quito es el lugar en todo el reino del Perú en el que más abunda este rico metal como he sido a menudo informado." ${ }^{43}$

En realidad, en esta época los únicos centros mineros de la jurisdicción de la ciudad de Quito eran los relativamente nuevos placeres de oro de Las Barbacoas y del Chocó, la parte alta del Río Ñapo (en el oriente o cuenca del Amazonas) y las antiguas y poco productivas minas de veta de Zaruma, en las partes altas de la cuenca del río Tumbes. Minas más ricas se habían trabajado en Zamora, al este de Loja, entre los años de 1550 y 1610, pero estas explotaciones y sus abusivos capataces fueron destruidos por una serie de levantamientos indígenas. La decadencia y el contrabando redujeron a fines del siglo XVII a casi nada el quinto o los impuestos de minería que se pagaban en Quito. Pero cualquier oro que adquiría la Audiencia, se iba directamente a Lima o a Cartagena para tranquilizar a los impacientes funcionarios del tesoro. Por ejemplo, los 17.000 pesos en bañas de oro, aunque parte de él en oro en polvo, confiscados por la Audiencia en agosto de 1679 de los bienes de un comerciante muerto, en diciembre del mismo año ya estaban en Cartagena para el pago de las fortificaciones. ${ }^{44}$

42 Cartas del Tribunal y Audiencia, Mayo 20 de 1684 a abril 3 de 1712, ANHQ Real Hacienda, caja 5, ff. 195-96 (sin fumar, ca. 1695). Según el funcionario: -...pues en ninguna caxa del Reyno se experimenta atrasamiento tan notorio...».

43 Dampier, A New Voyage, 110.

44 Tanteo de Quito, 1679, ANHQ Real Hacienda, caja 4, ff.29,55v. 
Sin saber de la escasez de metálico y otros problemas financieros, más y más bucaneros abundaban en el Pacífico a mediados de la década de 1680, más que todo como respuesta a los esfuerzos adelantados por los ingleses en el Caribe en contra de los bucaneros. En efecto, su número creció a casi 1.000 a finales de 1685, después de que muchos cruzaron por la vía del Darién en Panamá. En el Golfo de Panamá Swan y Davis se encontraron con varias bandas de piratas ingleses comandados por los Capitanes Townley, Harris y Knight y con varios bucaneros franceses o filibusteros, incluyendo a los capitanes Grogniet, Le Pierd, Lescuier, Desmarais y al escritor de Diarios Raveneau de Lussan. A finales de los años de 1680, estos bucaneros, la mayoría con comisiones expiradas, otorgadas por el gobernador del asentamiento francés de Petit Goave en la Hispaniola, acosaron las rutas de los barcos y las poblaciones de la costa del Perú español. A pesar de su número, este enorme grupo de piratas no pudo mantenerse unido al momento de enfrentarse con defensas organizadas. El encuentro con un escuadrón naval o armadilla frente a la isla Pacheca en el golfo de Panamá en mayo de 1685, dejó a los piratas esparcidos, revelándose su falta de disciplina. Los bucaneros, también divididos por razones de religión y lengua, se esparcieron en media docena de grupos. Swan, Ringrose y Dampier en el Cygnet navegaron hacia el norte a lo largo de la costa de la Nueva España con la esperanza de interceptar un galeón de Manila. Sus intentos fallaron y antes de irse para las Indias Orientales y Madagascar en 1686, Ringrose y cincuenta miembros de la tripulación fueron asesinados en una emboscada cerca al pueblo mejicano de Senticpac, al noroccidente. ${ }^{46}$ Como en Arica y Tumaco en el pasado, las iniciativas locales de defensa a lo largo de la supuestamente desprotegida costa Pacífica, ocasionalmente podían ser mortales.

Otros, más que todos grupos de bucaneros franceses, asaltaron por más de un año la costa de Centroamérica, antes de intentar, a comienzos de 1687, un ataque a Guayaquil. La expedición de Guayaquil, dirigida por Francois Grogniet, no fue tan exitosa para los defensores locales. En las primeras horas de la mañana del 20 de abril de 1687, Grogniet y una fuerza de 300 bucaneros entraron en la ciudad, por tres puntos distintos y la tomaron completamente después de una corta batalla. Guayaquil fue saqueada, quemada y obligada a pagar rescate. Al corregidor, Femando Ponce de León, se le dejó para que enfrentara los cargos de cobardía e incompetencia. Curiosamente, el tesorero de Guayaquil, Alonso de Enderica, también fue acusado de retener municiones, sobre todo la pólvora de los soldados. ${ }^{47}$ Cualquiera que hubiera sido la causa de la derrota, lo cierto fue que los piratas disfrutaron del botín de guerra en la cerca-

45 Para una traducción al inglés de este diario, ver Wilbur, Raveneau de Lussan. El término "filibustero proviene originalmente del holandés, vrijbuiter, que fue traducido al inglés como «freebooter», después adaptado al francés como flibustier y posteriormente, traducido nuevamente al inglés como «filibuster»; Se utiliza como sinónimo de "bucanero".

46 Gerhard, Pirates of the West Coast of New Spain Pág 173.

47 Bradley, The Lure of Peru, Pág. 151, y Juan Freile Granizo, ed, Actas del Cabildo Colonial de Guayaquil, T. VI, 1682-1689, Guayaquil Publicaciones del Archivo Histórico de Guayas, 1980, Pág. 165-66. Los soldados reclamaron que el costo de la pólvora era sustraído de sus salarios por el tesorero, de ahí que afectados económicamente no querían hacer fuego contra sus enemigos. 
na Isla de Puna durante algunas semanas antes de separarse. Se dispersaron debido al compromiso adquirido con la armadilla financiada por el sector privado, comandada por los capitanes vizcaínos Nicolás de Igarza y Dionisio de Artunduaga. Grogniet había muerto de las heridas recibidas en la captura de Guayaquil y su banda, ahora dirigida por el Capitán Le Picard, regresó por tierra al Caribe, siguiendo la vía del río Segovia en diciembre de $1687 .^{48}$

Desafortunadamente para los españoles, los filibusteros franceses no se habían retirado totalmente de sus mares. A mediados de diciembre de 1689, algunos habitantes del noroccidente de Las Barbacoas, probablemente pescadores indígenas, se encontraron con un pequeño bote repleto de españoles perdidos frente a la Isla Gorgona. Estos ex-prisioneros, pasajeros del buque mercante San Francisco Javier, habían sido capturados en octubre de 1689, al suroeste de Guayaquil. Con sorpresa, habían sobrevivido a una odisea de casi tres semanas en el mar, que había comenzado en Las Galápagos. Fueron capturados y luego dejados a la deriva por una banda desordenada de bucaneros franceses, la mitad sobrevivientes del contingente de Guayaquil y la otra mitad recién llegados al mar del Sur. A pesar de que a los piratas, al mando de un tal capitán Franco, les habían asegurado que no había entre ellos navegantes con experiencia, los náufragos lograron alcanzar el continente tras un extraordinario viaje de 1.400 kilómetros. Un conocido militar de Las Barbacoas, Bartolomé Estupiñán y Flores, tomó algunos testimonios de varios de los sobrevivientes y los envió a Quito. La información contenida en estos testimonios proporcionaría a los funcionarios españoles valiosos indicios en cuanto a la fuerza, los hábitos y las motivaciones que tenían estos últimos bucaneros del mar del Sur.

El informe, fechado el día de navidad de 1689, fue presentado como un mensaje que debía enviarse al gobernador de Popayán y al virrey peruano. Contiene testimonios juramentados de los pasajeros rescatados, incluyendo al propietario del Javier, Francisco de la Rain. Otro sobreviviente, Pedro de la Milla, reconstruyó parte de la historia, explicando que él y sus camaradas de abordo habían dejado la Isla Puna, frente a Guayaquil el 6 de octubre de 1689, para navegar hacia el Callao. ${ }^{49}$ Después de nueve días de navegación comenzaron a bordear Cabo Blanco. Un tercer testigo, el comerciante de telas de Quito llamado Antonio Fernández de Miranda, proporcionó nuevos detalles. El afirmó que cerca a Cabo Blanco, aproximadamente a las 6 a.m., el piloto vio una nave de vela. A las 9 a.m. él había identificado la embarcación como una nave enemiga, a juzgar por sus pendones (gallardetes) y por los brillantes cuchillos que esgrimían los miembros de su tripulación. ${ }^{50}$ El Javier, según Fernández, trato de

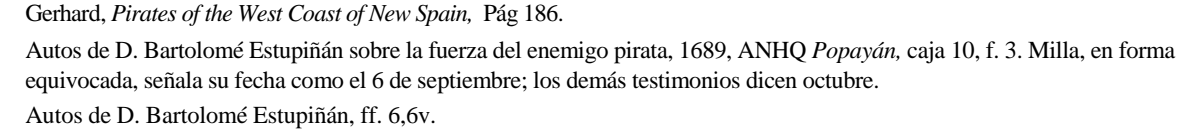


escapar, pero el barco perseguidor le disparó y dio en el blanco. Al buque mercante le comenzó a entrar agua y la rendición se volvió inevitable. Tanto Milla como Fernández estuvieron de acuerdo en que el Javier fue entregado a los piratas alrededor de las cuatro o cinco de la tarde. Después los bucaneros se separaron, algunos buscando más premios en las cercanías, mientras que el buque mercante capturado fue conducido directamente hacia las Islas Galápagos. En el camino se descubrió que los piratas, quienes habían gastado dos meses reconociendo las islas y cazando tortugas, estaban tan ansiosos de cambiar de dieta, como lo estaban por la plata del rescate. Aparte del Javier, tenían en su posesión un bergantín goleta nacarado, capturado frente a la isla de La Plata durante el mes de julio, junto con su propietario, Martín Izquierdo y su modesta tripulación de esclavos. ${ }^{51}$

Milla y Fernández explicaron el interés que animaba a los piratas, testificando que ante todo estaban necesitando un nuevo barco, porque el de ellos estaba «corroído» ${ }^{52}$. Esta embarcación, llamada la Urqueta, aparentemente había tenido mucho trabajo en el Pacífico y, entre otras averías, tenía la que le había sido hecha en una batalla frente a Acapulco. Milla testificó sobre el poder de ruego de los bucaneros, diciendo que contó hasta seis cañones en la Urqueta y el peso de las bolas de hierro alcanzaba entre cinco y ocho libras. Otro pasajero, con el que había hablado, se metió en la bodega, en donde contó por lo menos catorce cañones más, todos aperados con cabalgadas. Esta información le hizo saber que los piratas planeaban armar el Javier. Fernández diría posteriormente que los bucaneros habían descargado tablas robadas para comenzar a preparar un nuevo barco, haciéndole agujeros a los lados para sus cañones. $^{53}$

Desafortunadamente, los sobrevivientes dieron descripciones muy vagas sobre los piratas. Milla y Fernández estuvieron de acuerdo en que el enemigo lo componían 110 hombres, «menos veinte negros que les servían en todo lo que podían y veinte navegantes indígenas tomados de [nuestro] barco y de un barco cargado de harina». ${ }^{54}$ Fernández suministró igualmente detalles sobre los prisioneros africanos. Indicó que ocho de ellos habían sido parte de la tripulación de perleros de Martín Izquierdo, cuatro eran de la «Provincia de Quito», prisioneros del Javier, y los otros ocho eran diestros artilleros que habían venido con los piratas desde el Caribe. Milla se refirió a los europeos simplemente como franceses, pero Fernández dijo que un puñado eran ingleses y

51 Autos de D. Bartolomé Estupiñán, f. 3. Los buceadores profesionales esclavos eran numerosos a lo largo de esta costa. Sus propietarios, a menudo comerciantes de Guayaquil, los alquilaban a buscadores de perlas y para el salvamento de náufragos, a un jornal establecido o tasa diaria (no sueldo) de 1 peso.

52 Autos de D. Bartolomé Estupiñán, f. 3v. Textualmente dijeron: -ya pasada de broma», haciendo referencia a la broma de la lombriz, que acortó la vida laboral de muchos barcos en las aguas tropicales americanas.

53 Autos de D. Bartolomé Estupiñán, ff. 7v,8. Es posible que La Urqueta, "la ballena asesina", como en Cuca, no fuera el nombre del barco, sino "Urquita", el diminutivo de urca.

54 Autos de D. Bartolomé Estupiñán, f. 3v. 
holandeses, estos últimos apreciados como «Luteranos y Calvinistas»? ${ }^{5}$ Esta información difería considerablemente de la que dio otro prisionero Juan Martín Ibáñez. Este era el piloto del Javier y, a diferencia de los otros, permaneció con los bucaneros hasta su liberación dos años más tarde en 1691. En un despacho enviado al virrey peruano, Ibáñez dijo que la tripulación pirata consistía de sólo ochenta y nueve hombres: treinta y cuatro franceses, cuatro holandeses, un inglés (el piloto), y los otros cincuenta eran esclavos africanos e indígenas. O bien Milla y Fernández exageraron o la relación de Ibáñez se hizo más tarde, cuando la banda se había separado, cambiado y reagrupado, como era costumbre hacerlo entre las pandillas de piratas. $^{56}$

Como fue corroborado por otros testigos, ni Milla ni Fernández exageraron las dificultades que enfrentaron los pasajeros después de que los dejaron a la deriva en el barco Javier. En un gesto de buena voluntad, poco convincente, los bucaneros prepararon esta embarcación con dos pequeños botes y embarcaron a los prisioneros con sólo treinta botijas (large jugs) de agua y una pequeña cantidad de carne, maíz y bizcochos para que compartieran entre cuarenta y tres adultos. El propietario del Javier, Francisco de la Rain, dijo que era sólo por la gracia de Dios que habían logrado llegar al continente; ninguno en esta barca dijo, incluyéndose él mismo, "conocía el man». ${ }^{57}$ En las Galápagos los prisioneros, seguros de que perecerían, le rogaron a los piratas que no los abandonaran en el mar. En una reunión abierta, cuyo tema era el destino de los prisioneros, algunos de los piratas, afirmó Fernández, habían considerado darles un barril de harina más grande. Sin embargo, esta idea fue rechazada por otros miembros de la tripulación, lo que hizo que los prisioneros se lamentaran de su desgracia. Después de muchas prédicas y consultar con el piloto del Javier, cuyos consejos debieron ser buenos, el grupo fue empujado fuera de borda. ${ }^{58}$

Después de diez y ocho días en el mar, los sobrevivientes fueron vistos cerca a la boca del río Guapi, justo al este de la Isla de Gorgona y al sur de los campos mineros de Timbiquí. Según un miliciano local, Josef de Quiñones, los encontraron en un estado deplorable. Quiñones, quien recogió a los náufragos, testificó que fue a buscarlos con el fin de "remediar sus necesidades y conocer qué desgracias habían caído sobre ellos". ${ }^{59}$ Los oficiales de Santa María del Puerto enviaron comida y otras pro-

55 Autos de D. Bartolomé Estupiñán, f. 7v.

56 El cálculo del tiempo que Ibáñez estuvo entre los filibusteros, de casi dos años, está en Manuel Moreyra y Paz-Soldan y Guillermo Céspedes del Castillo, eds., Colección de cartas de virreyes, Conde de Mondova, 3 vols., Lima, Instituto Histórico del Perú. 1954, T. I, Pág. 208-17.

57 Autos de D. Bartolomé Estupiñán, f. 2v. Hay un informe sobre un barco llamado San Francisco Javier llegando a Tumaco en enero de 1685 (Cuentas de la real caja de las Balbacoas, f.34). Era probablemente el mismo barco capturado por los filibusteros en 1689 a pesar de que su dueño estaba alistado como Vicente Botín. En este primer viaje el Javier, piloteado por un indígena de Guayaquil, cargaba sal sacada de las minas de Punta Santa Elena.

58 Autos de D. Bartolomé Estupiñán, f. 2v.

59 Autos de U. Bartolomé Estupiñán. f. 5v. 
visiones para aliviar a los sobrevivientes y pidieron a la Audiencia que les remitiera dinero para ayudarlos a que siguieran su viaje hacia el Callao. Muy poco dinero llegó y el bienestar de los sobrevivientes fue dejado, en su mayor parte, en manos de los vecinos de Barbacoas. Estos últimos esperaban que su servicio y colaboración con las víctimas y los interrogatorios que les hacían serían recompensados de algún modo por la Audiencia.

Pero la Audiencia, estaba más interesada en los planes de los piratas, que en las necesidades de los náufragos, y en el testimonio de Fernández que era especialmente útil. Por sus conversaciones con los filibusteros supo que no tenían intenciones de saquear la costa, sino que preferían robar cualquier barco desarmado que pudieran capturar a corta distancia de la costa. El estaba seguro de que huirían del Pacífico al ver los primeros barcos de guerra. ${ }^{60}$

El informe le sugería a la Corona que ésta apenas era una simple banda de ladrones de mar, y no otra gran masa de bucaneros capaces de repetir el desastre de Guayaquil de 1687. Debido a que los informes de los filibusteros eran inconsistentes con respecto a sus planes y proyectos, el informe de inteligencia dado por el piloto del Javier, Juan Martín Ibáñez, fue la fuente más confiable. ${ }^{61}$ En su largo testimonio Ibáñez manifestó que después de un año de estar navegando por el Pacífico español, los piratas dirigidos por el Capitán Franco, estaban cansados de asaltar a los comerciantes comunes y corrientes de la costa, que iban cargados con telas y vinos. Deseaban obtener un tesoro fácil. Entonces comenzaron a presionar a Ibáñez con el fin de obtener información sobre las vías que frecuentaban las naves y sobre todo preguntaron sobre Gorgona y Barbacoas. Aparentemente se encontraban divididos sobre si debían intentar ir o no a la tierra adentro. También, como en el pasado, los ahora desnutridos filibusteros franceses se encontraban desesperados por obtener comida y agua. Ibáñez lo describió su interrogatorio de la manera siguiente:

"...al llegar el dos de julio a una latitud de 2 grados [N], los piratas me preguntaron si había agua en la isla de Gorgona o en Barbacoas, a lo cual respondí que había navegado regularmente por estas aguas en buques de guerra y había fondeado aquí pero que nunca había ido a tierra, por lo que al oírme decir esto se enfurecieron conmigo y me amenazaron con cortarme la cabeza, con el objeto de tranquilizar a los otros el comisario me pegó y me dio una paliza con una caña y el capitán Franco me ordenó retirarme a la proa, de tal forma que no me pudieran maltratar más...". ${ }^{62}$

Autos de don Bartolomé Estupiñán, f.7v. Textualmente dijo: "...y que especuló la yntensión del enemigo por aver parlado con diferentes de ellos y sacó el que su disinio era componer el vaxel apresado y buscar presas en las castas del Peni y que si reconosían navios de guena juyrían y que no venían a pelear sino es a junar y que en baxando el armada a Panamá avían de correr..."

61 El único documento elaborado desde la perspectiva francesa que se conservó flie publicado por E Duceré, Journal de bord d'un flibuster (1686-1693) aprés un manuscrit de la Biblioteque Nationale, Bayona, A. Lamaigniére. 1894. 
Si Ibáñez estaba diciendo la verdad, les hubiera podido evitar a los aislados pueblos mineros de Las Barbacoas otra confrontación con los bucaneros. Al final, la ignorancia y el deseo de consumir cosas distintas a bizcochos y tortugas de mar, al igual que la oscuridad de la espesa jungla que aparecía ante ellos, persuadió a esta última banda de bucaneros del mar del Sur a abandonar la caza de botines y retornar a Europa. La tripulación del capitán Franco parece que atravesó el Estrecho de Magallanes a fines de 1693 y llegó a Francia en septiembre de 1695. La era de los bucaneros en el Pacífico español había terminado.

La provincia de las Barbacoas no fue un objetivo central en el amplio contexto de la piratería del mar del Sur, pero los efectos de la depredación marítima sobre la región y sus habitantes a finales del siglo XVII fueron muy importantes y duraderos. A pesar de verse forzados a financiar su propia defensa, las élites locales sacaron provecho de la amenaza de los piratas, al recibir títulos por su servicio militar. Algunos de sus miembros, como Bartolomé Estupiñán y Flores y Juan Godoy y Prado, utilizaron sus títulos para cimentar sus posiciones en la economía local, minera y comercial, sacando ventaja de toda transacción. Otros utilizaron los títulos y peticiones de servicio contra los bucaneros, para obtener apoyo a sus peticiones de concesiones que el gobierno otorgaba y que comprendían desde entregas de encomiendas vacantes, hasta "fondas" (travelers' inns). Segundo, los grupos indígenas de la frontera, como los Cayapas y los afro-indígenas de las Esmeraldas, utilizaron la amenaza de los bucaneros para evitar la conquista total de sus territorios, argumentando que ellos necesitaban ser considerados como centinelas. Para ellos los bucaneros fueron una excusa que mantuvo su propia autonomía, principio que apoyaron los residentes de las misiones. A los esclavos, a las personas libres de color y a otros sujetos no se les permitieron libertades similares, cuando los bucaneros fueron una amenaza. Sin embargo, el establecimiento de una fuerza miliciana de cascasen Barbacoas creó algunos incentivos de cooperación con los españoles, evitando posiblemente una rebelión. En suma, los bucaneros, con ataques inconsecuentes y rápidos sobre la costa de esta región minera y marginal, alteraron en forma inconsciente el equilibrio de los poderes internos en los años subsiguientes.

En la Audiencia de Quito la amenaza pirata de los años 1680 y 1690 tuvo también consecuencias de gran trascendencia. La pérdida de Guayaquil en 1687 condujo a acusaciones y tensiones exacerbadas entre las élites de los Andes y las de la costa. Más concretamente, la reconstrucción de la ciudad en otro sitio y la pérdida temporal del embarque de mercancías en el principal puerto de la Audiencia fue muy costoso. En Quito las reservas de la Real Audiencia comenzaron a disminuir en un momento en que los pagos del situado, la defensa costera y los socorros se aumentaron. De otro

62 Moreyra y Céspedes, Colección de cartas, Pág. 213 (N.T. Traducido del ingles) 
lado, la fábrica de pólvora en Latacunga adquirió importancia e incluso sacó provecho de la creciente amenaza bucanera. A pesar de que los ingresos por concepto de pólvora eran suficientes como para compensar las deudas acumuladas del situado, la expansión de la planta (subsidiada con trabajo forzado) generó nuevas ganancias tanto a la tesorería real, como a diferentes contratistas. Varios arquitectos, expertos en mampostería, carpinteros, armeros y otros artesanos, tanto en la costa como en las tierras altas, debieron beneficiarse de forma similar a partir de la creciente demanda por sus productos y servicios. Al igual que en las Barbacoas, los caciques indios y otros en la región de Guayaquil buscaron -y recibieron- recompensas por los servicios en contra de los invasores piratas. ${ }^{63}$ Por lo tanto se puede argumentar que mientras que las consecuencias de piratear en la costa de la Audiencia de Quito a finales del siglo XVII fueron más que todo negativas, sobre todo para los comerciantes, algunos grupos en la sociedad colonial de hecho se beneficiaron por la amenaza de la invasión. En un período en el que las guarniciones y navíos profesionales fueron considerados muy caros y la protección de los puertos fue crítica, los residentes costeros locales vieron la amenaza bucanera, no como un obstáculo, sino como una oportunidad para el progreso personal y en grupo.

63 Freile Granizo, Actas del Cabildo Colonial de Guayaquil, Pág. 107-113- Se llama a Miguel de Saracuaya cacique y gobernador de Yanco pueblo en honor al servicio que él y su gente realizaron en la construcción de empalizadas en Guayaquil. 